\title{
Effect of Exercises Guidelines Brochure on Daily Living Activities and Disease Symptoms for Patients with Idiopathic Parkinson's Disease
}

\author{
Ghona Abd El-Nasser Ali ${ }^{1 *}$, Attyiat Hassan Hussein ${ }^{2}$ \\ ${ }^{1}$ Medical -Surgical Nursing Department, Faculty of Nursing, Sohag University, Egypt \\ ${ }^{2}$ Medical-Surgical Nursing Department, Faculty of Nursing, Assiut University, Egypt
}

DOI: $10.36348 /$ sjnhc.2020.v03i04.004

| Received: 16.03.2020 | Accepted: 23.03.2020 | Published: 30.04.2020

*Corresponding author: Ghona Abd El-Nasser Ali

\section{Abstract}

Parkinson's disease is a neurodegenerative disease with symptoms that affect many aspects of daily life. Aim: This study aimed to assess the effect of exercise guidelines brochure on daily living activities and disease symptoms for patients' with idiopathic Parkinson's disease. Research Design: Pre-posttest research design. Sample: Sixty adult patients from both sex their age range between (40-65) years. Setting: The study was conducted in neurology department and its outpatient clinic at Sohag University Hospital. Tools: Two tools were used: first tool interview questionnaire sheet, second tool Unified Parkinson Disease Rating Scale (UPDRS). Results: The present study revealed that there were statistically significant differences between pre and post application of exercises guidelines regarding activities of daily living, and disease symptoms. Conclusion: Exercises guidelines were effective in improving daily living activities and disease symptoms for patients with Parkinson's disease. Recommendation: Exercise program for Parkinson's disease patients should be available in the neurology department and outpatient clinic at Sohag University Hospital.

Keywords: Parkinson's Disease, Daily Living Activities, Disease Symptoms, Nurse's Role.

Copyright @ 2020: This is an open-access article distributed under the terms of the Creative Commons Attribution license which permits unrestricted use, distribution, and reproduction in any medium for non-commercial use (NonCommercial, or CC-BY-NC) provided the original author and source are credited.

\section{INTRODUCTION}

Parkinson's Disease (PD) is a multi-system and neurodegenerative disease with genetic and environmental factors affecting about 7 to 10 million persons worldwide, which result in deficits in the production of neurotransmitters, including dopamine [1]. It is characterized by tremor, bradykinesia, stiffness, and impaired postural reactions. Motor disorders are compound and combined negatively affecting the patient's health. Tremor and stiffness are associated with worsening manual dexterity as well as postural changes such as akinesia and camptocormia [2].

Daily living activities with PD is typically a challenge, as movement disorders, postural instability, and other signs and symptoms can compromise the functional capacity, independence and patient need assistance in performing daily activities [3]. According to Khedr [4] an estimated 7-10 million people worldwide suffer from Parkinson's disease, affecting both sexes and races, while the prevalence of PD in Egypt was varied in different governorates and ranged from 53 to 557/105 populations, and the highest age- specific was recorded among males than females, and among subjects less than 75 years old.

The most important non-pharmacological treatment for PD patients is physical exercise and physiotherapy. Data available in the recent literature reviews indicate that any therapeutic plan would concentrate on: cognitive movement strategies, cueing strategies and enhanced physical capacity, and equilibrium. Different training programs for PD patients have been designed and evaluated but only specific training strategies, tailored and customized for each patient, may produce improvements in gait speed and stride length, minimize motor and balance symptoms considering, that this approach may ameliorate the symptoms as well as the overall physical incapacity, reduce the risk of falls and injuries, and ultimately improve quality of life [2]. Cusso et al., [5] added that exercise also improves non-motor symptoms, such as apathy, depression and fatigue.

Physical exercises such as running, walking, strength training, and whole-body vibration is a beneficial, low-risk, cost-effective intervention that promotes overall health and aims to improve motor and non-motor symptoms in PD [6]. So regular exercises 
and physiotherapy should be given a central place in the medical treatment of PD as a supplement to the best medical care [7].

Several studies have been done all over the world regarding the effect of physical exercises on motor and non-motor symptoms on patients' with Parkinson's disease. One of them is a study that was done in Columbus by Park et al., [8] who evaluated the effects of formal physical activity on Parkinson's postural instability and noted that the physical activity was beneficial for non-motor symptoms in PD. In another study of Adeloye et al., [9] which assesses the effect of physical activity on motor symptoms of PD, and found that physical activity such as balance and coordination training can improve muscle tropism and postural stability and strength. Such activities can also alleviate the symptoms as well as the overall physical disability, decrease the danger of injuries, and eventually improve QOl and social interaction.

In the study done in Canada by Lauze et al., [10] to assess the effects of physical activity in PD, who reported that the intervention of the therapeutic physical activity has positive effects on physical and functional capacities. Based on the above, this present study aimed to assess the effect of exercise guidelines brochure on daily living activities and disease symptoms for patients with idiopathic Parkinson's disease.

\section{Significance of the study}

Over the last decade, there has been a massive increase in the number of studies indicating the avails of exercise for people with PD. Physical exercises are important for people with PD because it helps maintain balance, improve mobility, gait, muscle strength and the ability to perform daily living activities. In addition to this study is the first in our district which can help such a group of patients to have less complications and return to daily living activities. So, we sought to attempt to establish exercises guidelines for patients with Parkinson's disease to improve their daily living activities and reduce the disease symptoms.

\section{AIM OF THE STUDY}

This study aimed to assess the effect of exercise guidelines brochure on activity of daily living and disease symptoms for patients with idiopathic Parkinson's disease.

Research hypothesis: To fulfill the aim of the study, the following hypothesis was formulated:

After receiving the exercise guidelines, patients with Parkinson's would have higher mean scores of daily living activities and improve disease symptoms than before receiving the guidelines.

\section{PATIENTS AND METHOD}

Research design: Pre-posttest research design was used to collect the data of the study.

\section{Technical Design}

Setting

The study was conducted in neurology department and its outpatient clinic at Sohag University Hospital.

\section{Sample}

Sixty adult patients with idiopathic Parkinson's disease with the level of disease on the Hoehn and Yahr [11] scale $(\leq 3)$, their ages ranged from (40-65) years old from both sexes (male and female), free from other disabling diseases that affect movement and gait, memory and steady pharmacological treatment.

The sample size was calculated to be 60 patients according to the following equation to Steven K Thompson (2012).

\section{Sample size}

$$
n=\frac{N \times p(1-p)}{\left.\left[N-1 \times\left(d^{2} \div z^{2}\right)\right]+p(1-p)\right]}
$$

Where:

$$
\begin{aligned}
& \mathrm{N}=\text { Total patient population size }(70) \\
& \mathrm{Z}=\text { Confidence level is } 0.95 \text { and is equal } 1.96 \\
& \mathrm{D}=\text { The error ratio is } 0.05 \\
& \mathrm{P}=\text { Property availability ratio and neutral }=0.50
\end{aligned}
$$

Tools: Data pertinent to the study were collected, utilizing the following:

\section{Two Tools}

Tool I: Patient's assessment sheet

It was designed by the researcher, it consists:

- Socio-demographic data about patients (age, gende $r$, level of education, occupation, marital status).

- Medical data of patients: include duration of disease.

\section{Tool II: Unified Parkinson Disease Rating Scale (UPDRS)}

Developed by Fahn and Elton [13]. The UPDRS was used to characterize the severity of PD at the time of testing. It includes 42 items divided into 4 parts: (a) mentation, behavior, and mood, and it contains 4 items, (b) daily living activities it contains 13 items, (c) motor part it contains 14 items, and the last part (d) contains 11 items. The UPDRS is administered by an interview.

\section{Scoring System}

The Unified Parkinson's Disease Rating Scale (UPDRS) has 4 parts. Each part has multiple points that are individually scored, using (0) for normal or no problems, (1) for slight problems, (2) for mild problems, (3) for moderate problems, and (4) for severe problems, in the most of the scale items, except items 
35-38 \& 40-42, the scoring system was yes take(1) or no take(0). These scores are tallied to indicate the severity of the disease. The maximum score is 147 points is possible and is indicative of the most severe disability, whereas 0 represented no disability.

\section{Exercises Guidelines Brochure}

Constructed by researchers after reviewing current national and international literature [9, 14-17]. The exercise guidelines brochure included importance, types of exercises and techniques for each type of exercise. Such as stretching, strengthening, balance, breathing exercises. The exercise guidelines brochure also included some helpful tips to make physical activity more useful and enjoyable such as:-

- Wear comfortable clothing and athletic footwear

- Wear closed shoes with flat heels, never wear slippers

- $\quad$ Breathe deeply while exercising

- Exercise making sure no pain develops

- Perform exercise 30 minutes at least 2-3 days each week.

- Exercise regularly and make it a part of daily life

\section{Operational Design}

Data were collected from January 2019 to November 2019 over eleven months. The study was carried out on three phases: the preparatory phase, implementation phase, evaluation phase.

\section{Preparatory Phase}

This phase stared by:

During this phase, an exploratory visit was carried out to the neurology department and outpatient clinic to know the patient's follow rate and appropriate time for data collection. A review of current and past, local and international related literature as articles, journals, magazines, and textbooks was done, study tools were formulated, and this phase ended by contents validity and pilot study. Contents validity to check relevance, clarity, comprehensiveness, easiness and content of the tools. Pilot study was conducted on $10 \%$ of the sample to evaluate the applicability and clarity of the tools. Some questions have been restructured and rephrased to provide the most accurate response, according to the results obtained, these patients were excluded from the current study. To facilitate the implementation of exercise guidelines researchers prepared the training places, teaching aids and media (pictures, videotapes, and handouts).

\section{Implementation Phase}

At initial interview, the researchers presented herself to initiate a line of communication in order to facilitate the implementation of the tools. The patient was interviewed individually and assessed by using (tool I \& tool II) pre application of exercise guidelines. The exercise guidelines were implemented to the patients in three successive sessions. Teaching sessions were applied on an individual basis in the attendance of one of the family members to confirm patient support and assist the patient to perform the exercises at home. The duration of each session was about (30-45 minutes). The first session included an orientation about the guidelines, its purpose, importance and types of exercises. The second session started with a summary about contents discussed in the previous session and technique for each type of exercise. The third session included demonstration for each type of exercise as stretching, strengthening, balance, breathing exercises, posture and walking. For each type, several practical training and activities such as standing, sitting, waking up, range of joint and muscle movement by holding position and relaxing. Where, all PD patients' included in this study were received at the beginning of exercise about 10 minutes for warming (walking, moderate stretching and breathing training), followed by performing exercises about (30-40 minutes), and at the end of exercise the patient takes 5-10 minutes to cool down. Every patient obtained a copy of Arabic exercise guidelines brochure, and asked the patients to keep the brochure for recalling the exercises, and being motivated for following it at home for 2-3 days per week. Also, Phone contacts were preserved between the researchers and patients to ensure follow-up visits in the out-patient clinic.

\section{Evaluation Phase}

Post-test was carried out after one month the researchers have assessed daily living activities and disease symptoms for all patients after application of exercise guidelines during follow up in the outpatient neurological clinic by using (tool II). Comparisons of pre and post findings were carried out using an appropriate statistical test in order to determine the effect of applying exercise guidelines on daily living activities and disease symptoms.

\section{Administrative Design}

Permission to carry out the study was obtained from the responsible hospital authorities of the neurological department at Sohag University Hospital, after explaining the aim, and purpose of the study and to obtain their cooperation, also an oral permission from the participating patients or guardians.

\section{Ethical Considerations}

Prior to data collection, an official letter was issued to the director of Sohag University Hospital to carry out the study after explaining the nature and purpose of the study. Also, the research proposal was approved from the Ethical Committee in the Faculty of Nursing, Sohag University. Oral consent was obtained from all respondents or guardians to participate in the study, after explaining the aim and nature of the study. Likewise, each patient was reported that the right to refuse to participate and or withdraw from the study without any rationale any time. Confidentiality and anonymity will be assured. 


\section{Statistical Design}

Data were revised, coded, entered and analyzed using SPSS (Ver.16). Data was expressed using number, percentage, mean $\pm \mathrm{SD}$. Comparison of means was performed using student t-test. Also, Pearson's correlation coefficient (r) was used to tested the correlation between variables. Significance level was considered at $\mathrm{p}<0.05$.

\section{RESULTS}

Table-1: Distribution of socio-demographic characteristics of studied patients

\begin{tabular}{|l|l|l|}
\hline & No. $(\mathbf{n = 6 0})$ & \% \\
\hline Age: & \multicolumn{2}{|l|}{} \\
\hline$<50$ years & 22 & 36.7 \\
\hline 51 - 60 years & 24 & 40.0 \\
\hline$>60$ years & 14 & 23.3 \\
\hline Mean \pm SD (Range) & $58.22 \pm 9.64(40-65)$ \\
\hline Gender: & \multicolumn{2}{|l|}{} \\
\hline Male & 46 & 76.7 \\
\hline Female & 14 & 23.3 \\
\hline Marital status: & & \\
\hline Married & 44 & 73.3 \\
\hline Widow & 16 & 26.7 \\
\hline Education level : & & \\
\hline Educated & 30 & 50.0 \\
\hline Illiterate & 30 & 50.0 \\
\hline Job: & & \\
\hline Employee & 18 & 30.0 \\
\hline Worker & 2 & 3.3 \\
\hline Retired/ unemployed & 40 & 66.7 \\
\hline Duration of disease: & & \\
\hline$<1$ year & 18 & 30.0 \\
\hline 1 year to < 3 years & 30 & 50.0 \\
\hline 3 year < 5 years & 8 & 13.3 \\
\hline$>5$ years & 4 & 6.7 \\
\hline
\end{tabular}

This table shows that, the highest percentage was between the ages of 51-60 years. Also, there was a predominance of male, married, and no work. As regarding duration of the disease the majority of studied patients were 1 year to $<3$ years.

Table-2: Daily living activities and disease symptoms for studied patients pre and post application of exercises guidelines

\begin{tabular}{|l|l|l|l|}
\hline \multirow{2}{*}{ Items } & Pre & Post & \multirow{2}{*}{ P-value } \\
\cline { 2 - 3 } & Mean \pm SD & Mean \pm SD & \\
\hline - Mentation, Behavior and Mood & $2.23 \pm 0.82$ & $1.03 \pm 0.67$ & $0.000^{*}$ \\
\hline - Activities of daily living & $2.27 \pm 0.79$ & $1.10 \pm 0.66$ & $0.000^{*}$ \\
\hline - Motor examination & $2.23 \pm 0.82$ & $1.10 \pm 0.66$ & $0.000^{*}$ \\
\hline - Complications of therapy & $2.23 \pm 0.82$ & $1.10 \pm 0.66$ & $0.000^{*}$ \\
\hline
\end{tabular}

Table-2 Illustrates that, there were statistically significant differences between pre and post application of exercise guidelines regarding activities of daily living, and disease symptoms.

Table-3: Comparison between the total mean score of daily living activities and disease symptoms pre and post application of exercises guidelines

\begin{tabular}{|l|l|l|l|}
\hline UPDRS & Pre & Post & P-value \\
\hline Mean \pm SD & $94.43 \pm 31.48$ & $50.40 \pm 24.41$ & $0.000^{*}$ \\
\cline { 1 - 2 } Range & $46.0-124.0$ & $7.0-85.0$ & \\
\hline \multicolumn{4}{|l|}{ *. Statistically significant at $\mathrm{p} \leq 0.05$} \\
\end{tabular}

This table reveals that daily living activities and disease symptoms in patients with Parkinson's disease were improved after the application of exercise guidelines. 
Table-4: Relation between socio-demographic characteristics, daily living activities and disease symptoms for studied sample (pre test)

\begin{tabular}{|l|l|l|l|}
\hline \multirow{2}{*}{$\begin{array}{l}\text { Socio-demographic } \\
\text { characteristics }\end{array}$} & \multicolumn{2}{|c|}{ Daily living activities and disease symptoms } & \multirow{2}{*}{ P-value } \\
\cline { 2 - 3 } & Mean \pm SD & Range & \multirow{2}{*}{$0.000^{*}$} \\
\hline Age: & & & \\
\hline < 50 years & $64.18 \pm 26.38$ & $46.0-124.0$ & \\
\hline $51-60$ years & $104.92 \pm 19.72$ & $84.0-124.0$ & \multirow{2}{*}{0.055} \\
\hline$>60$ years & $124.00 \pm 0.00$ & $124.0-124.0$ & \\
\hline Gender: & & & \multirow{2}{*}{0.305} \\
\hline Male & $100.48 \pm 30.29$ & $46.0-124.0$ & \\
\hline Female & $74.57 \pm 28.75$ & $46.0-124.0$ & \multirow{2}{*}{0.817} \\
\hline Marital status: & & & \\
\hline Married & $90.82 \pm 32.03$ & $46.0-124.0$ & \\
\hline Widow & $104.38 \pm 29.58$ & $46.0-124.0$ & \\
\hline Education level: & & & \\
\hline Educated & $95.80 \pm 30.82$ & $46.0-124.0$ & \\
\hline Illiterate & $93.07 \pm 33.16$ & $46.0-124.0$ & \\
\hline
\end{tabular}

This table reveals that, there were significant differences between daily living activities, disease

symptoms, and age of studied patients in pre exercises guidelines.

Table-5: Relation between Socio-demographic characteristics, daily living activities and disease symptoms for studied sample (post test)

\begin{tabular}{|l|l|l|l|}
\hline \multirow{2}{*}{$\begin{array}{l}\text { Socio-demographic } \\
\text { characteristics }\end{array}$} & \multicolumn{2}{|l|}{ Daily living activities and disease symptoms } & \multirow{2}{*}{ P-value } \\
\cline { 2 - 3 } & Mean \pm SD & Range & \multirow{2}{*}{$0.006^{*}$} \\
\hline Age: & & & \\
\hline < 50 years & $33.82 \pm 16.59$ & $10.0-46.0$ & \\
\hline 51 - 60 years & $55.50 \pm 24.36$ & $7.0-85.0$ & \multirow{2}{*}{$0.011^{*}$} \\
\hline$>60$ years & $67.71 \pm 20.65$ & $45.0-85.0$ & \\
\hline Gender: & & & \multirow{2}{*}{0.937} \\
\hline Male & $56.43 \pm 22.81$ & $12.0-85.0$ & \\
\hline Female & $30.57 \pm 19.32$ & $7.0-46.0$ & \multirow{2}{*}{0.759} \\
\hline Marital status: & & $7.0-85.0$ & \\
\hline Married & $50.18 \pm 25.35$ & $12.0-85.0$ & \\
\hline Widow & $51.00 \pm 23.22$ & & \\
\hline Level of education: & & $12.0-85.0$ & \\
\hline Educated & $49.00 \pm 21.06$ & $7.0-85.0$ & \\
\hline Illiterate & $51.80 \pm 28.04$ & & \\
\hline
\end{tabular}

This table reveals that, there were significant differences between daily living activities, disease symptoms, and age of studied patients in post application of exercise guidelines. Also, there were significant differences between gender, daily living activities, and disease symptoms of studied patients.

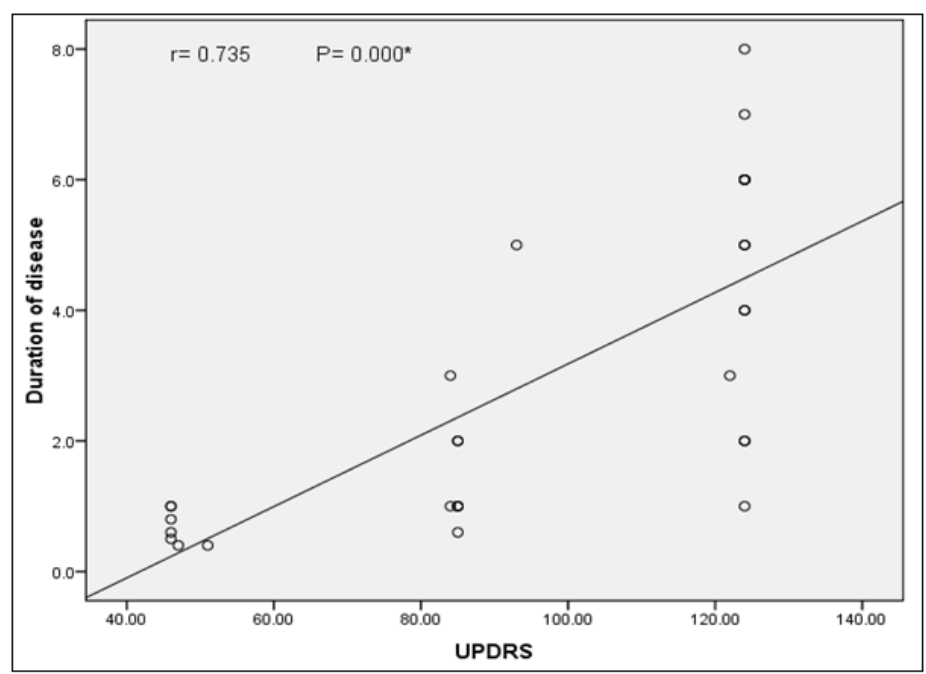

Fig-1: Correlation between duration of disease, daily living activities and disease symptoms for studied patients 
This figure illustrates that there were statistically significant differences between the duration of disease, daily living activities, and disease symptoms for studied patients.

\section{DISCUSSION}

Exercises is a safe, low-risk, cost-effective intervention that promotes overall health and aims to improve motor and non-motor symptoms in Parkinson's disease. The present study showed that; the highest percentage of the study group was between the ages of 51-60 years. Also, there was a predominance of males. This finding was similar to Gultekin et al., [18] who stated that, Parkinson's disease is more common in elderly males, and most cases occurring after the age of 50 .

In the present study, the mean scores of daily living activities and disease symptoms showed improvement after exercise guidelines than their level before it. There were highly statistically significant differences between pre and post application of exercise guidelines. In the studies done by De Carvalho et al., [14]; Fayyaz et al., [15] who revealed the benefits of exercise in improving cognition, depression, fatigue, and sleep, and there were emerging evidence suggesting that people with PD who exercise may also experience improvement in these symptoms. In the same line, Ellis $\&$ Rochester [19] they stated that the different forms of specific and effective exercises when combined likely support functional gains including improved gait, mobility, daily living activities, and reduced fall rate in persons with PD.

Also, agreed with Lauzé et al., [10] who reported that the results indicate that physical activity interventions had a positive impact on physical and functional capacities, as well as a moderate effect on disease symptoms and psychological and social aspects of life in addition to, improving activities of daily life well. Cusso et al., [5] added that exercises also improve non-motor symptoms, such as apathy, depression, and fatigue. Nurses can encourage PD patients to aware of care for example, during exposure to risk for falls, depression and other problems that are reduced by regular exercise.

Brown [20] stated that from the early to late stages of PD, people can experience decreased walking, balance, and daily activities. But when participating in regular exercise programs showed improvement in many aspects of day to day function and general wellbeing including improved walking speed, improved activity tolerance, decreased tiredness, improved balance and increased strength. This also was supported by Nakae \&Tsushima [21] who reported that, guidance in home exercises patients with PD can be effective in making self-exercises a habit, improving range of motion and muscle strength, and reducing the time spent in a recumbent position. The intervention had positive effects on self-exercises frequency and duration and on self-recognition in terms of a reduction in the number of main complaints due to PD symptoms and a reduction in fear of falling.

Mark \& Sage [22] stated that Parkinson's disease (PD) is a chronic movement disorder that is best managed with a combination of close monitoring, medication, education, support, and exercises. In addition, Li et al., [23] reported that several exercise modalities improve the symptoms of Parkinson's disease, where exercises work on improves balance, gait, and physical function, it considered inexpensive and typically has no negative side effects.

Bikmullina \& Vilpponen [24] added that nurse's role involved in the education of PD patients is very demanding and important. Every nurse in primary and secondary health care settings, should be aware of various needs of PD patients and most effective methods of teaching a PD patient. The well planned and conducted patient education is a key to improved quality of life of the patient with such chronic conditions as PD. Patient education should begin by analyzing the condition of the patient and disease knowledge. Proper amount of time should be allocated for education and selected proper method and environment, considering drug schedules for patients, physical comfort and exercises and possible communication issues. The patient should be interested in the educational process as well as his family and caregivers.

Our study illustrated that there was a significant difference between daily living activities and the age of studied patients in pre and post application of exercises guidelines, while there was a significant difference between daily living activities and gender of studied patients only in post application. Also, there were statistically significant differences between duration of disease, daily living activities, and disease symptoms for studied patients.

This study finding was in the line with Santos et al., [25] who stated that our results showed that patients with PD younger than 60 years of age and with less than five years of the disease had a statistically significant improvement in the UPDRS scale. On the other hand, the present study was contradicted with Yaghoobi et al., [26] who found that, no significant differences between the mean of all demographic characteristics of subjects and activities of daily living.

The present study findings showed that, there was a significant difference between daily living activities and gender of studied patients only in post application. These results were compatible with the finding by Urell et al., [27]. In the same line Slezakova \& Zavodna [28] stated that, Parkinson's disease restricts the quality of life in areas such as mobility, daily 
activities, disease symptoms, emotional and cognitive functions most of the patients feel lower quality of life. Saha et al., [29] added that a significant improvement of activities of daily living and quality of life after participation in the patient education program for Parkinson's disease. Large variations in change scores found are indicating variation in benefit.

Dibble et al., [30] showed that physical activities in combination with pharmacological treatment it improved quality of life in addition to, the physical activities also could improve body structure and function and activity outcomes, by teaching and training PD patients in the use of movement strategies.

\section{CONCLUSIONS}

Based on the results of the present study, it can be concluded that:

Application of exercise guidelines when dealing with patients with Parkinson's disease showed a significant improvement in patient's daily living activities and disease symptoms.

\section{RECOMMENDATIONS}

1. Assessment of nurse's knowledge and practices in relation to the package of care provided to Parkins on's disease patients.

2. Developing strategies aimed to improve physical a ctivity for Parkinson's patients.

3. Exercise program for Parkinson's disease patients should be available in the neurology department an d outpatient clinic at Sohag University Hospital.

\section{REFERENCES}

1. Parkinson's Disease Foundation, Accessed 2 May 2016. http://www.pdf.orgl.

2. Borrione, P., Tranchita, E., Sansone, P., \& Parisi, A. (2014). Effects of physical activity in Parkinson's disease: A new tool for rehabilitation. World Journal of Methodology, 4(3), 133-143.

3. Ferreira, D. C., Wanderley, G., M. \& Lins, C., C. (2017). The perspective of caregivers of people with Parkinson's: an integrative review. Revista Brasileira de Geriatria e Gerontologia, 20(1): 99109.

4. Khedr, E. M.(2015). Prevalence of Parkinson's disease in Egypt: A review of community-based survey. International Conference on Parkinson's Disease \& Movement Disorders. Journal of Alzheimers Disease and Parkinsonism, 5(2): 42.

5. Cusso, M. E., Donald, K. J., \& Khoo, T. K. (2016). The impact of physical activity on non-motor symptoms in Parkinson's disease: a systematic review. Frontiers in medicine, 3(35):1-9.

6. Amara, A. W., \& Memon, A. A. (2018). Effects of exercise on non-motor symptoms in Parkinson's disease. Clinical therapeutics, 40(1), 8-15.

7. Redecker, C., Bilsing, A., Csoti, I., Fogel, W., Ebersbach, G., Hauptmann, B., Hellwig, B., \& Müngersdorf, M. (2014). Physiotherapy in
Parkinson's disease patients: recommendations for clinical practice. Basal Ganglia, 4: 35-38.

8. Park, A., Zid, D., Russell, J., Malone, A., Rendon, A., Wehr, A., \& Li, X. (2014). Effects of a formal exercise program on Parkinson's disease: a pilot study using a delayed start design. Parkinsonism \& related disorders,20(1), 106-111.

9. Adeloye, O. O., Olatunji, M. A., \& Olawuwo, S. (2019). Effect of therapeutic exercises on motor symptoms of Parkinson disease: A Mini Review. Mediterranean Journal of Basic and Applied Sciences(MJBAS).2019,3(2):214-217.

10. Lauzé, M., Daneault, J., \& Duval, C. (2016). The effects of physical activity in Parkinson's disease: a review. Journal of Parkinson's Disease, 6:685-698.

11. Hoehn, M. M., \& Yahr, M., D. (1967). Parkinsonism: onset, progression, and mortality. Neurology, 17(5), 427-427-442..

12. Thompson, S. K. (2012). Sampling, 3rd ed (Walter A. Shewhart and Samuel S . Wilks), 472.

13. Fahn, S., \& Elton, R. (1987). Members of the UPDRS Development Committee. In: Fahn, S., Marsden, C. D., Calne, D. B., Goldstein, M, eds. Recent Developments in Parkinson's Disease, Vol 2. Florham Park, NJ. Macmillan Health Care Information, 153-163, 293-304

14. De Carvalho, A. O., Sá Filho, A. S., MurilloRodriguez, E., Rocha, N. B., Carta, M. G., \& Machado, S. (2018). Physical exercise for Parkinson's disease: clinical and experimental evidence. Clinical practice and epidemiology in mental health: $C P \& E M H, 14,89-98$.

15. Fayyaz, M., Jaffery, S. S., Anwer, F., Zil-E-Ali, A., \& Anjum, I. (2018).The effect of physical activity in Parkinson's disease: a mini-review. Cureus, 10(7):1-4.

16. Barksdale, H., \& Oguh, O. (2016). Strategies to encourage physical activity in patients with Parkinson's disease: improving quality of life. Journal of Parkinsonism and Restless Legs Syndrome, 6:37-43.

17. Parkinson Society Canada. Physical Activity and Parkinson's Disease. https: // w ww.csep.ca / CM Files / Guidelines /specialpops/PSC_Physical_Activity_ resource and _chart_final\% 20 English \% 20 march2012.pdf

18. Gultekin, M., Sarılar, A. C., Ekinci, A., Erturk, G., \& Mirza, M. (2017). The Level of Knowledge of Parkinson's Disease among Nonprofessional Caregivers in a Movement Disorders Center in Turkey. Parkinson's Disease, Hindawi Parkinson 's Disease, 1-5.

19. Ellis, T., \& Rochester, L. (2018). Mobilizing Parkinson's disease: The future of exercises, Journal of Parkinson's Disease, 8(51):S95-S100.

20. Brown, L. (2014).Parkinson's disease and exercises, American Physical Therapy Association, Section on Neurology. www.neuropt.org 
21. Nakae, H., \& Tsushima, H. (2014). Effects of home exercises on physical function and activity in home care patients with Parkinson's disease. Journal of Physical Therapy Science, 26(11):1701-1706.

22. Mark, M. H., \& Sage, J. I. (2012). Patient information: Parkinson disease treatment optionseducation, support, and therapy. The American Parkinson Disease Association www.stlapda.org /content /pdfs/Young.

23. Li, F., Harmer, P., Fitzgerald, K., Eckstrom, E., Stock, R., Galver, J., Maddalozzo, G. \& Batya, S., S. (2012). Tai chi and postural stability in patients with Parkinson's disease. The New England Journal of Medicine, 366(6):511-519.

24. Bikmullina, R., \& Vilpponen, Z. (2013). Patient education among patients with Parkinson's disease. Helsinki Metropolia University of Applied Sciences, https ://core.ac.uk/download/pdf/38097917.pdf

25. Santos, V. V., Araújo, M. A., Nascimento, O. J., M., Guimarães, F. S., Orsini, M., \& de Freitas, M. R. (2012). Effects of a physical therapy homebased exercise program for Parkinson's disease. Fisioterapia em Movimento, 25(4), 709-715.
26. Yaghoobi, H., Mohammadi, S., Sardashti, S., Abbaspour, S., \& Hossein-Abadi, T. S. (2019). Comparison of the effect of aerobic and resistance training on cardiovascular risk factors in Parkinson's women. The Open Nursing Journal, 13(1):186-192.

27. Urell, C., Zetterberg, L., Hellström, K., \& Anens, E.(2019). Factors explaining physical activity level in Parkinson' s disease: A gender focus. Physiotherapy theory and practice, 1-10.

28. Slezakova, Z., \& Zavodna, V. (2013). Quality of life in patients with Parkinson's disease. Elizabeth College of Health and Social Work, Bratislava, Slovakia. Act Nerv Super Rediviva, 55(1-2):1-3.

29. Saha, R., Worth, P., \& Stamford, J. (2015). Assessing quality of life in Parkinson's in routine clinical settings. Neurology, 2015-14(6):12-14.

30. Dibble, L. E., Bo Foreman, K., Addison, O., Marcus, R. L., \& La Stayo, P. C. (2015). Exercises and medication effects on persons with Parkinson disease across the domains of disability: a randomized clinical trial. Journal of Neurologic Physical Therapy, 39(2):85-92. 